\title{
3D deep geothermal reservoir imaging with wireline distributed acoustic sensing in two boreholes.
}

\author{
Evgeniia Martuganova $^{1,2}$ and Charlotte M. Krawczyk ${ }^{1,2}$ \\ 1 Helmholtz Centre Potsdam, GFZ German Research Centre for Geosciences, 14473 Potsdam, Germany \\ 2 Department of Applied Geophysics, Technische Universität Berlin,10587 Berlin, Germany
}

Correspondence: Evgeniia Martuganova (evgeniia.martuganova@gfz-potsdam.de)

\begin{abstract}
Geothermal exploration will help moving towards a low-carbon economy and provide a basis for green and sustainable growth. The development of new practical, reliable methods for geophysical characterisation of a reservoir has the potential to facilitate a broader application of deep geothermal energy. At the Groß Schönebeck in-situ laboratory, a unique vertical seismic profiling (VSP) dataset was recorded in two $4.3 \mathrm{~km}$ deep geothermal boreholes using fibre optic cables in early 2017. The experiment set-up consisted of 61 vibrator points organised in a spiral pattern around the well site to ensure a proper azimuth distribution in the target reservoir section. Data were processed using a standard workflow for VSP. As a result, a detailed 3-dimensional $0.75 \times 1 \times 4.5 \mathrm{~km}$ size image around the existing boreholes was created using the Kirchhoff migration algorithm with restricted aperture. The imaging resolved small-scale features in the reservoir essential for the future exploration of the geothermal research site. Borehole data with vertical resolution up to $16 \mathrm{~m}$ revealed the existing depth variations of the Elbe basis sandstone horizon at $4.08-4.10 \mathrm{~km}$ depth and indications of an unconformity in the area where we expect volcanic rocks. In addition, in the borehole data a complex interlaying with numerous pinch outs in the Upper Rotliegend reservoir section (3.8 to $4 \mathrm{~km}$ depth) was discovered. Thereby, we demonstrate that wireline fibre optic data can significantly contribute to exploration by providing an efficient and reliable method for deep geothermal reservoir imaging.
\end{abstract}

\section{Introduction}

Measurements with a fibre-optic cable installed in diverse environments are widely applied for seismic data acquisition for versatile research topics such as urban seismology (Dou et al., 2017; Spica et al., 2020b; Yuan et al., 2020), glacial studies (Booth et al., 2020; Brisbourne et al., 2021; Hudson et al., 2021), geothermal exploration (Li and Zhan, 2018; Lellouch et al., 2021), volcanology (Nishimura et al., 2021) and underwater seismology (Spica et al., 2020a; Lior et al., 2021). Perhaps, one of the most well-studied distributed acoustic sensing (DAS) applications is cable deployment for data acquisition in boreholes. Measurements with a fibre-optic cable installed along the casing or behind the tubing are widely and successfully applied for borehole seismic data acquisition. 3D vertical seismic profiling (VSP) imaging results with permanent cable installation include applications for oil and gas exploration (Jiang et al., 2016; Shultz and Simmons, 2019; Zhan and Nahm, 2020), the monitoring of $\mathrm{CO}_{2}$ reservoirs (Humphries et al., 2015; Götz et al., 2018; Correa et al., 2019; Wilson et al., 2021), and for mineral exploration and mining (Bellefleur et al., 2020). 
Nevertheless, in a vast number of already drilled boreholes, only measurements with a wireline logging cable are feasible. Surveys with wireline installation, such as the dataset collected for petroleum exploration in China, near Tangshan, Hebei (Yu et al., 2016), are still quite unique and rarely found in the literature.

For geothermal exploration, a very limited number of wireline DAS with active seismic source was applied (Miller et al., 2018; Henninges et al., 2021). Data acquisition in a harsh environment, such as elevated temperatures, poses additional challenges in terms of the requirements for the instrumentation. Using optical cables, a detailed image of the subsurface can be created, using, for instance, seismic imaging techniques (Krawczyk, in review). In addition, the deployment is more efficient in terms of time and costs, in comparison with a standard installation of conventional borehole instruments. Therefore, data collection with an application of fibre optics technology can provide a reliable and efficient method for exploring and monitoring geothermal reservoirs. This paper presents results from one of the first applications of DAS VSP for deep geothermal exploration at the Groß Schönebeck geothermal research site down to $4 \mathrm{~km}$ depth.

\section{The Groß Schönebeck site}

The in-situ laboratory Groß Schönebeck is located in the Northern German Basin, one of Germany's main regions with deep hydrothermal resources. The joint research project RissDom-A (RissDominierte Erschließung in German: fracture-dominated exploitation) aims to gain expertise in sustainable energy production from low permeability geothermal reservoirs by developing Enhanced Geothermal Systems (EGS). The Buntsandstein sandstone formation and volcanic rocks of Lower Permian (Rotliegend) (Figure 1a) age are of interest for the direct use for the geothermal energy production (Blöcher et al., 2016). A successful geothermal exploration case study can lead to broader geothermal energy usage in the regions without hydrothermal potential. Moreover, the geological setting at the experiment site is typical for a broad part of Northern Europe. Therefore, the acquired knowledge from this case study can be applied to geothermal exploration programs in other areas with similar geological conditions.

To deepen the understanding of the geological structures interpreted on sparse vintage 2D seismic lines and locate possible faults within the area of interest, a high-resolution 3D reflection seismics acquisition campaign was carried out in February/March 2017 (Stiller et al., 2018; Krawczyk et al., 2019). The 3D surface seismic survey was designed to cover an area of $8 \mathrm{~km}$ by $8 \mathrm{~km}$, focusing on target reservoir depth from 4 to $4.3 \mathrm{~km}$. Since the studied geothermal reservoir zone is located at

50 a depth greater than $4 \mathrm{~km}$ and overlaid by Zechstein salt, it is a challenging target for exploration with conventional seismic methods.

\subsection{The distributed acoustic sensing vertical seismic profiling survey}

In contrast to surface seismics, VSP has the advantage of shorter reflection travel paths. Therefore, the amplitudes are theoretically less subjected to attenuation. As a result, this provides a better signal to noise ratio and broader frequency content. Thus, to improve the resolution of seismic data, which is limited due to the thick salt layer (more than $1 \mathrm{~km}$ ), and to provide detailed imaging around the existing boreholes, an extensive VSP experiment using wireline DAS technology was conducted prior the 


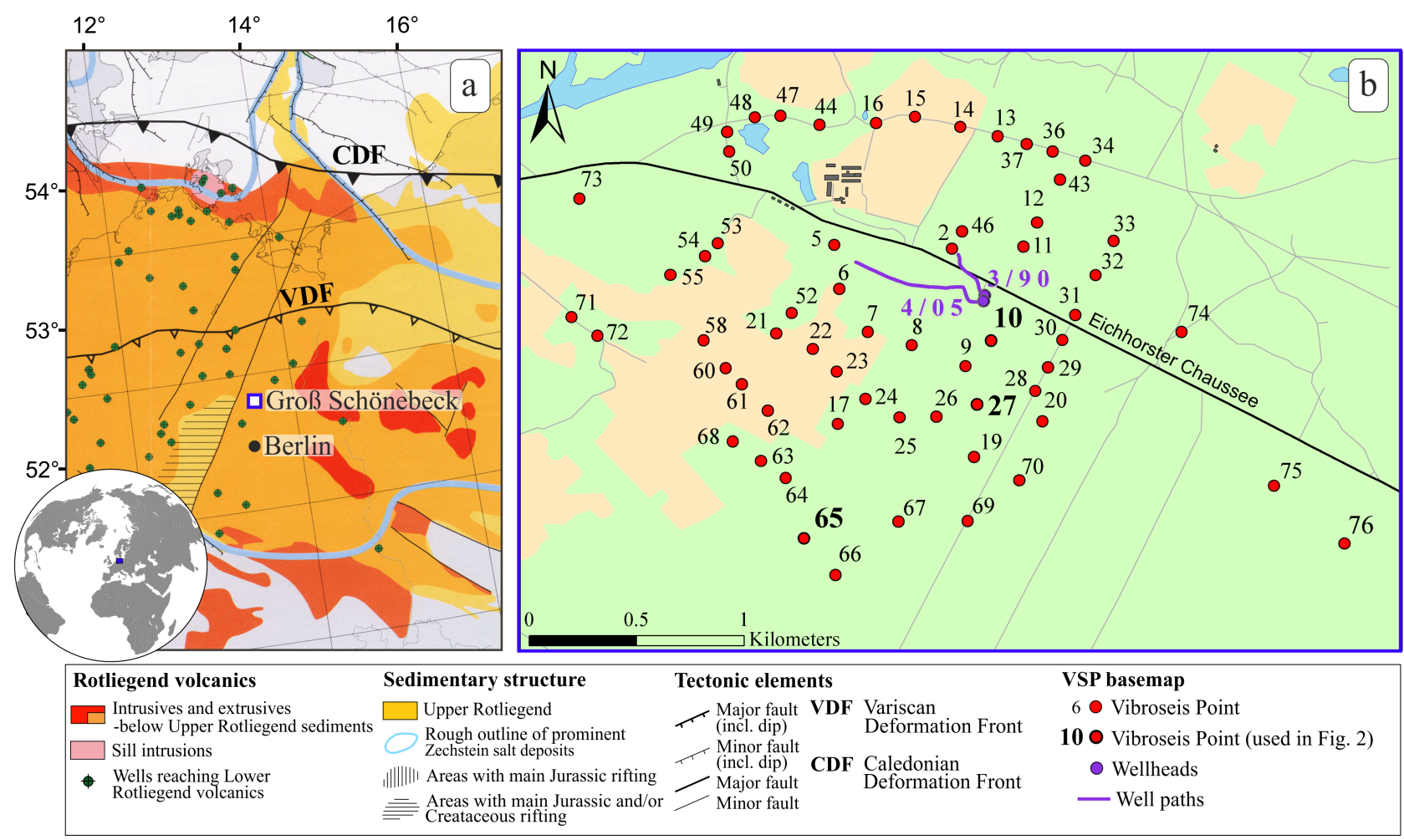

Figure 1. Location of the Groß Schönebeck geothermal site. (a) Rotliegend volcanics and sedimentary distribution in the Southern Permian Basin (compilation from Krawczyk et al. (2019)). (b) Base map of the Groß Schönebeck geothermal site with two boreholes (violet circles) in the centre and 61 VSP source points (red dots) arranged in a spiral pattern around.

main surface seismic experiment in February 2017. Two wireline hybrid cables (electrical and optical; from SLB (NOVA-F) and GFZ (Rochester) (Henninges et al., 2011) were temporarily deployed inside the casing of two deep water-filled boreholes. Nearly vertical well E GrSk 3/90 (maximum inclination $7.2^{\circ}$ ), which was formerly used for oil and gas exploration, and Gt GrSk 4/05 (maximum inclination $49^{\circ}$ ) form a geothermal doublet (Figure 1b). Two hDVS (heterodyne distributed vibration sensing) interrogator units from Schlumberger were connected to single-mode fibres and used to record the strain along the boreholes with $5 \mathrm{~m}$ spatial sampling. A 20-m gauge length was used for data recordings in the field. Later, this value was adjusted to $40 \mathrm{~m}$ for $\mathrm{E}$ GrSk 3/90 according to the velocity profile in the reservoir section to get an optimal $\mathrm{S} / \mathrm{N}$ ratio and preserve data resolution (Dean, Cuny, and Hartog, 2017). Data recorded in Gt GrSk 4/05 were used with only 20-m gauge length due to the loss of the raw fibre optical data.

The measuring campaign consisted of 1 start-up testing and 3 data acquisition days in total. The 61 vibrator source points (VPs) had a spiral layout around the target area with varying offsets from 188 to $2036 \mathrm{~m}$ around the boreholes to ensure a good azimuth distribution (Figure 1b). As seismic source, four heavy Mertz M12 Hemi 48 vibroseis trucks were used with a peak force of $200 \mathrm{kN}$ (45100 Ibf) each. All source units vibrated simultaneously at each VP location and guaranteed an average 
https://doi.org/10.5194/se-2021-138

Preprint. Discussion started: 15 November 2021

(C) Author(s) 2021. CC BY 4.0 License.

(c) (i)

vertical stacking fold of 16 per source location. A linear sweep of $10-112 \mathrm{~Hz}$ and $36 \mathrm{~s}$ length was used for data acquisition. Several VPs with larger offsets, were recorded using a sweep from 10 to $96 \mathrm{~Hz}$.

Due to the cable failure in Gt GrSk 4/05, the recording of the last $500 \mathrm{~m}$ in the reservoir section was lost, and the maximum surveyed depth is limited to $3716 \mathrm{~m}$ measured depth (MD). Moreover, we were only able to record 18 VPs from the originally planned 61 because the cable was retrieved from the borehole after only 1 day of acquisition. This event led to significantly reduced subsurface coverage of the survey design between the two wells. In E GrSk 3/90, we recorded the planned 61 VPs and the maximum surveyed depth is at $4251 \mathrm{~m}$ MD. Nevertheless, recorded datasets from this borehole have inconsistent amplitudes caused by unknown reasons, which requires further investigations (Henninges et al., 2021).

Overall, all mentioned details make this dataset acquired at the Groß Schönebeck geothermal research site very challenging for data processing. We will focus on the processing flow in the next section of the paper, which we used to successfully identify reservoir details.

\section{Data processing}

For the 3D DAS VSP dataset a processing flow containing typical elements was adapted to the Groß Schönebeck survey specifics and then applied to the data (see Table 1). The major steps and parameters details are discussed in the following sub chapters.

Table 1. 3D DAS VSP data processing flow.

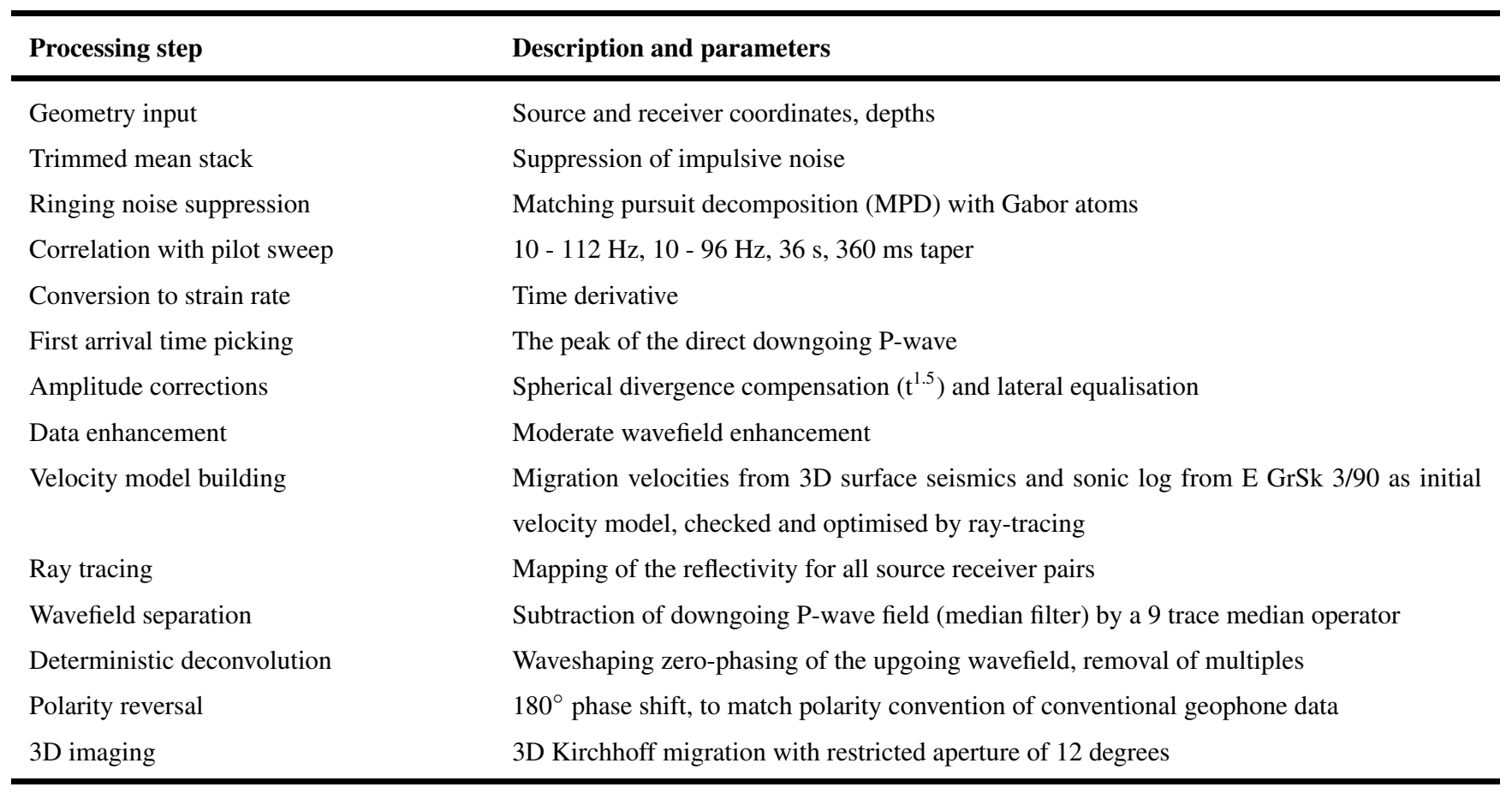




\subsection{Data preconditioning} elevations and true vertical depths calculated using boreholes trajectories.

Each VP recording set contained a various number of recorded sweeps, ranging from 12 to 37 . Data within each VP were sorted on increasing MD and vertically stacked using a trimmed mean stack, which helped to exclude amplitude outliers.

Wireline records are frequently suspected to ringing noise, which occurs in those depth intervals of the boreholes where the cable can move freely and creates resonances with a fundamental frequency and higher overtones in the amplitude spectrum.

Figure 2 shows selected VPs with variable offsets such as $214 \mathrm{~m}, 510 \mathrm{~m}$ and $1411 \mathrm{~m}$ for the borehole E GrSK 3/90 after preprocessing (vertical stacking, correlation with the pilot sweep and subsequent differentiation) and denoising. All seismograms have a distinct $\mathrm{P}$ wave arrival; however, they are heavily dominated by a coherent characteristic striped or zig-zag noise. For instance, depth intervals 890 - 966, 1588 - 1816 m for VPs recorded in E GrSK 3/90 are contaminated by this type of noise (Figure 2 panels a, b, c). It appears that the noise distribution does not change significantly from one VP to another and affects shallower depth regions more than the deeper ones. Also, it can be noted that borehole Gt GrSk 4/05 has more noisy intervals, in comparison with E GrSK 3/90, and with higher amplitudes, for example, for depth regions at 873 - 980, 2177 - 2177, 3330 - 3409 m (Figure 2 panels g, h, i).

Ringing noise clearly represents a challenging problem and should be tackled by means of data processing. We did a few denoising test using different denoising approaches, including Burg adaptive deconvolution and Time-Frequency domain attenuation. The optimal denoising result was achieved using a novel approach based on matching pursuit decomposition (MPD) using Gabor atoms, described in Martuganova et al. (2021). According to this method we formed an overcomplete Gabor dictionary to decompose the original signal. Then using atomic parameters such as amplitude, frequency and position in time we determined parts of the signal representing slapping of the cable and subtracted them from the data to perform the denoising. To improve the S/N ratio of the data we applied the MPD denoising method after stacking, but before correlation to avoid smearing the noise by the correlation process. The results of denoising for two boreholes given in Figure 2 on panels d, e, $\mathrm{f}$ and j, k, 1 for E GrSK 3/90 and Gt GrSk 4/05 respectively. MPD denoising eliminated almost all noise on the seismograms and significantly improved traceability of the reflections, which are no longer obscured by the ringing noise.

After denoising, the correlation with the pilot sweep and time-differentiation to convert data to the strain-rate were applied to the data. This was followed by amplitude corrections (spherical divergence correction and lateral equalisation) and moderate wavefield enhancement. Also, measured depths were converted to true vertical depth below seismic datum elevation (TVDSD), and later in the text, we refer to it as depth.

\subsection{Velocity model building and ray tracing}

Several independent data sources were used to determine the velocity function for main stratigraphic layers of the region and 
https://doi.org/10.5194/se-2021-138

Preprint. Discussion started: 15 November 2021

(c) Author(s) 2021. CC BY 4.0 License.
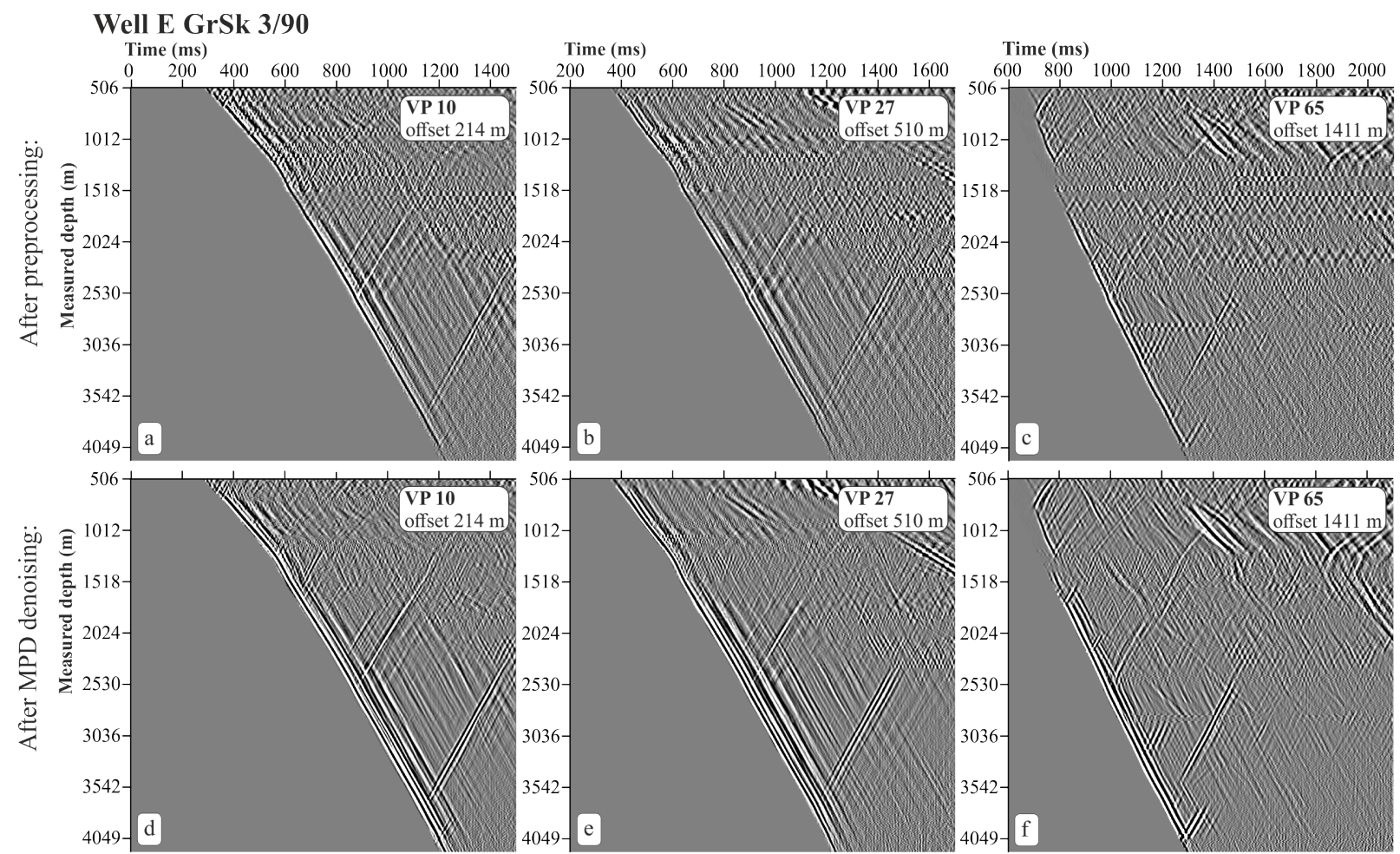

Well Gt GrSk 4/05
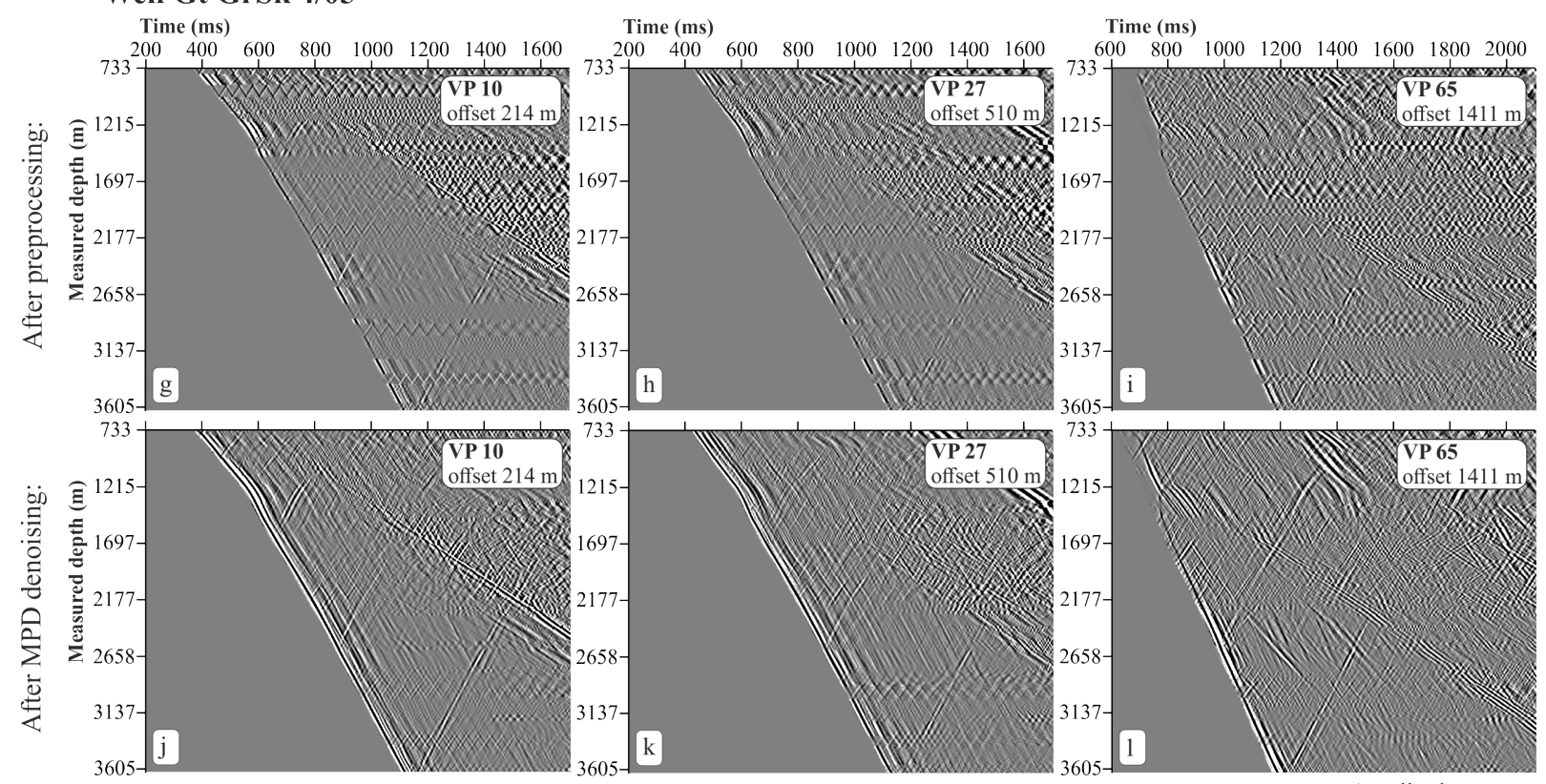

Amplitude

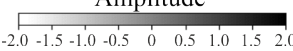

Figure 2. Common-source gathers displays for different source positions with offsets $214 \mathrm{~m}, 510 \mathrm{~m}$ and $1411 \mathrm{~m}$ after preprossessing (a), (b), (c) for well E GrSk3/90 and (g), (h), (i) for well Gt GrSk4/05; after noise subtraction using MPD denoising method and a moderate coherency enhancement (d), (e),(f) for well E GrSk3/90 and (j), (k), (l) for well Gt GrSk4/05. 
with the Lizarralde smooth inversion method (Lizarralde and Swift, 1999) to get the main trend (Figure 3a black curve). Then, velocity values were updated according to calibrated sonic log data (Figure 3a thin grey curve) and the surface seismics velocity cube (Figure 3a, dark blue curve). The model was checked using the ray-tracing results, and iteratively optimised to minimize the drift between the recorded and modelled arrival times for the rig shot at source position 10.

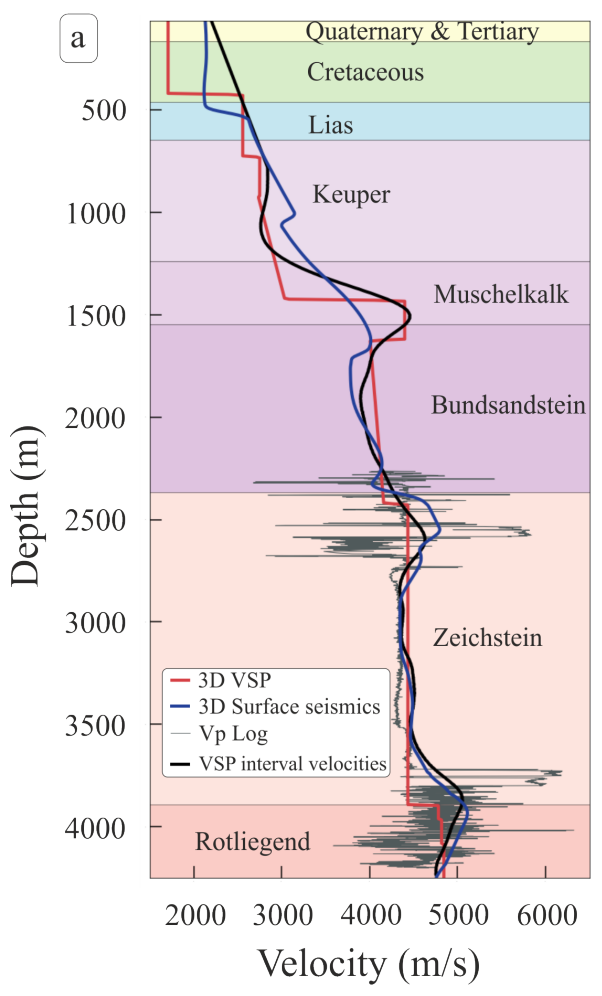

Stratigraphy Legend

$\square$ Quaternary and Tertiary

Cretaceous

Lower Jurassic (Lias)

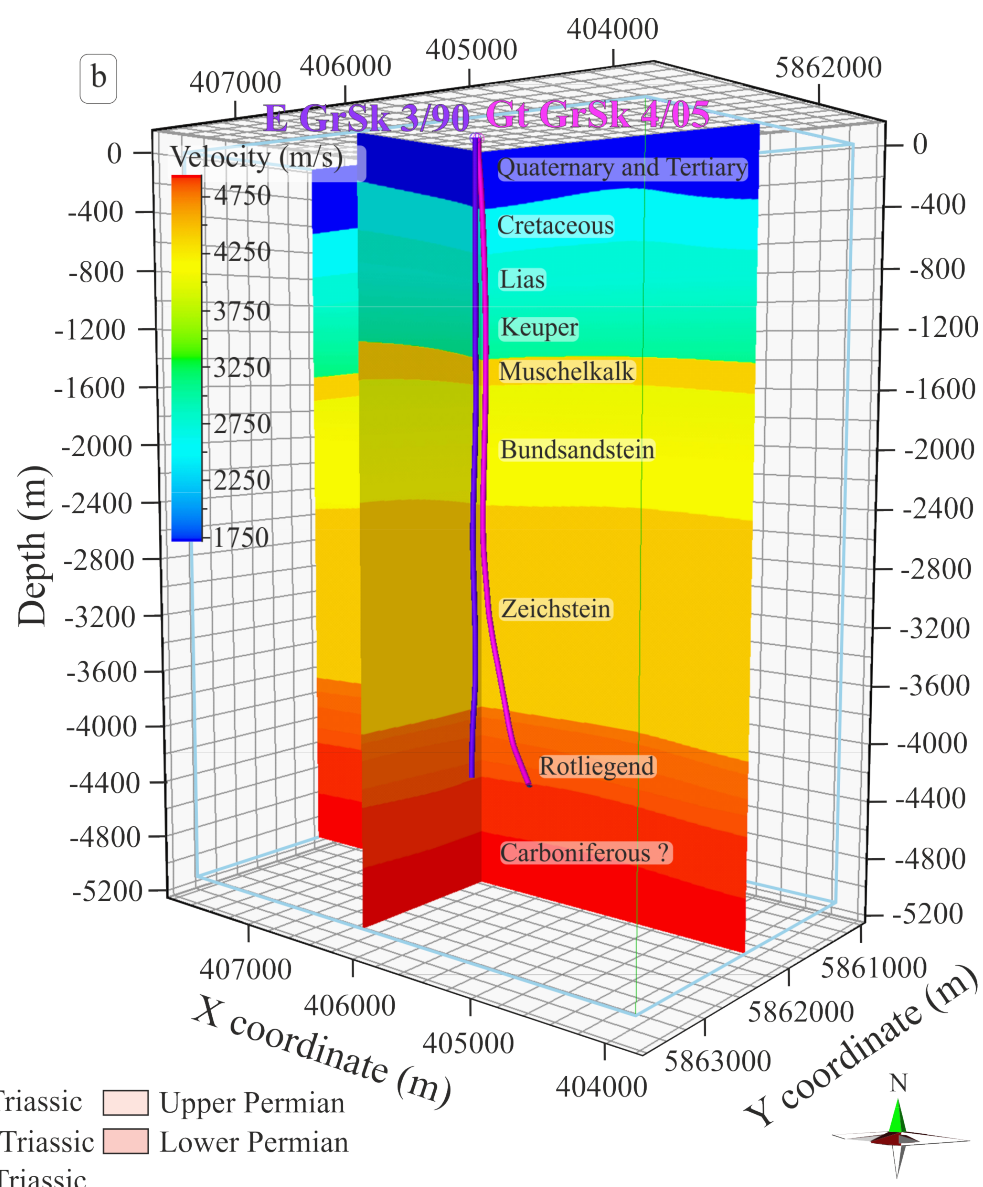

Lower Triassic

Figure 3. Velocity information at the Groß Schönebeck research site. (a) Velocity functions at the borehole E GrSk3/90 location. Red line - the curve extracted from the 3D DAS VSP velocity model shown in (b); dark blue line - the curve extracted from the 3D velocity model used for the 3D surface seismics prestack depth migration; thin grey line - sonic log measurement; thick black line - VSP interval velocities derived from the first break peaks using the method of smooth inversion after Lizarralde and Swift (1999). (b) 3D DAS VSP velocity model created using top formation surfaces to build an initial velocity model, which was then checked and optimised according to ray tracing results.

To improve the fit for far offset VPs a small anisotropic drift was included into the model. Thomsen's P-wave anisotropy parameters (Thomsen, 1986), namely $\epsilon$ and $\delta$, for transversely isotropic (TI) media, $4 \% \delta$ and $16 \% \epsilon$ were selected for all layers down to the top salt. These parameters were tested and optimised, which allowed to reduce the standard deviation of drift for the longer offset VPs. Finally, all VPs were ray-traced through the constructed model, and reflection points (loci) for 
https://doi.org/10.5194/se-2021-138

Preprint. Discussion started: 15 November 2021

(c) Author(s) 2021. CC BY 4.0 License.

\section{(c) (i)}

each source-receiver pair were extracted. The comparison of the picked arrival and ray-traced times were compared to check whether the smallest misfit for all available data was achieved. The average of the mean model drift for all VPs is $2.43 \mathrm{~ms}$ for the borehole E GrSk3/90 and $7.7 \mathrm{~ms}$ for Gt GrSk 4/05, respectively.

The layered 3D DAS VSP velocity model follows the geological model (Moeck et al., 2009) and has constant or vertical gradients indicated by the sonic log data (Figure 3a red curve; Figure 3b). Potential lateral variations are not accounted for. The values vary from $1750 \mathrm{~m} / \mathrm{s}$ in the upper Quaternary and tertiary layers to $5000 \mathrm{~m} / \mathrm{s}$ in the Rotliegend (Permian) reservoir section.

\subsection{Data preparation for migration}

The next processing step includes wavefield separation and deconvolution. To separate the up-going wavefield the downgoing P-wave field was subtracted using a median filter. We tested a few different wavefield separation techniques (F-K transform, FP transform), and the cleanest result was obtained by applying the median filter. This filter delivered a cleaner residual up-going response with less smearing of the amplitude artefacts, and also preserves the resolution of data. Prior to deconvolution, the up-going wavefields were scaled by -1 changing the polarity of DAS data to match the required European convention (increase $\mathrm{AI}=$ negative number on a trace.) The separated wavefield was deterministically deconvolved, using individual downgoing responses as trace-by-trace operators, followed by a bandpass filter $8,12-70,80 \mathrm{~Hz}$ and a front mute.

To further prepare the data for imaging, source statics corrections were applied. Additionally, data were moved to premigration depth using a model-based stretch to map points according to reflection-point loci. Due to significant data quality variations between shots caused by unknown changes in the response of the fibre, the amplitudes across all data points were normalised using RMS amplitude values calculated in a depth window selected on the most prominent salt sequence reflection event. Each trace then was scaled by the inversed RMS trace value. The resulting pre-migrated seismograms were used as input for 3D imaging.

\subsection{D imaging}

For imaging, a commercial 3D Kirchhoff migration algorithm (VSProwess Ltd.) was used. Calculated via ray-tracing, the reflection-point loci for each source-receiver pair is interpolated and used to map each processed sample to its modelled image point coordinate. This is routinely known as VSP common depth point (CDP) mapping (Dillon and Thomson (1984). Once the reflectivity is mapped approximately to the correct location it can be binned. An efficient surface tracking algorithm is used to find all those bins within the specified aperture angle intersected by the reflection ellipsoid.

For migration, we used a $12.5 \mathrm{~m}$ x $12.5 \mathrm{~m}$ horizontal and a $5 \mathrm{~m}$ depth bin size. After extensive testing, we chose a 12-degree aperture which allowed to sum the main reflections best and to preserve image details. In addition, the migration operator removed some of the imaging artefacts. A scaled version of each mapped sample is summed into each of these bins (normally cos-squared window). A by-product of migration is a bin count cube. A 3D bin density image along two lines and the depth slice at $4100 \mathrm{~m}$ are shown in Figure 4. This 3D visualisation discloses holes in the seismic coverage at $4100 \mathrm{~m}$ depth. Gaps in coverage are particularly noticeable east of the observation well. To avoid imaging artefacts, bin density information was used 
https://doi.org/10.5194/se-2021-138

Preprint. Discussion started: 15 November 2021

(c) Author(s) 2021. CC BY 4.0 License.

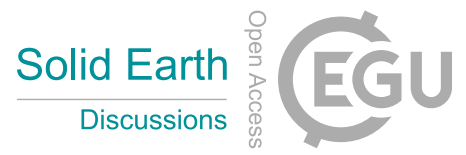

first to normalise amplitudes in the 3D DAS VSP volume. Afterwards, the bin density information is utilized to identify high uncertainty areas where the image fold is sparse and to clip the resulting cube in accordance to it. Furthermore, bin density cube was employed to determine an area with a reasonable coverage (Figure 4a, dark blue rectangle) for further clipping of horizon maps.
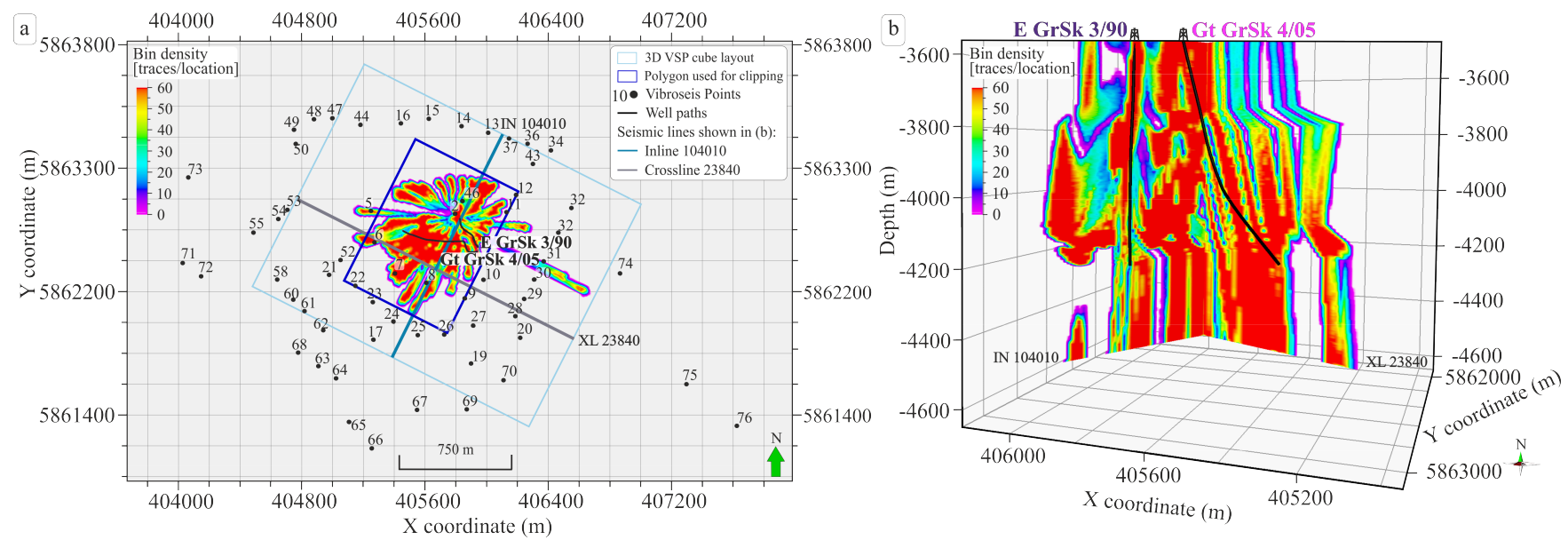

Figure 4. Examples of the ray coverage for the study area. Depth slice of a 3D bin density volume at $4100 \mathrm{~m}$ depth (a). 3D visualisation of two seismic lines in the $3 \mathrm{D}$ bin density cube (b) (for location see a).
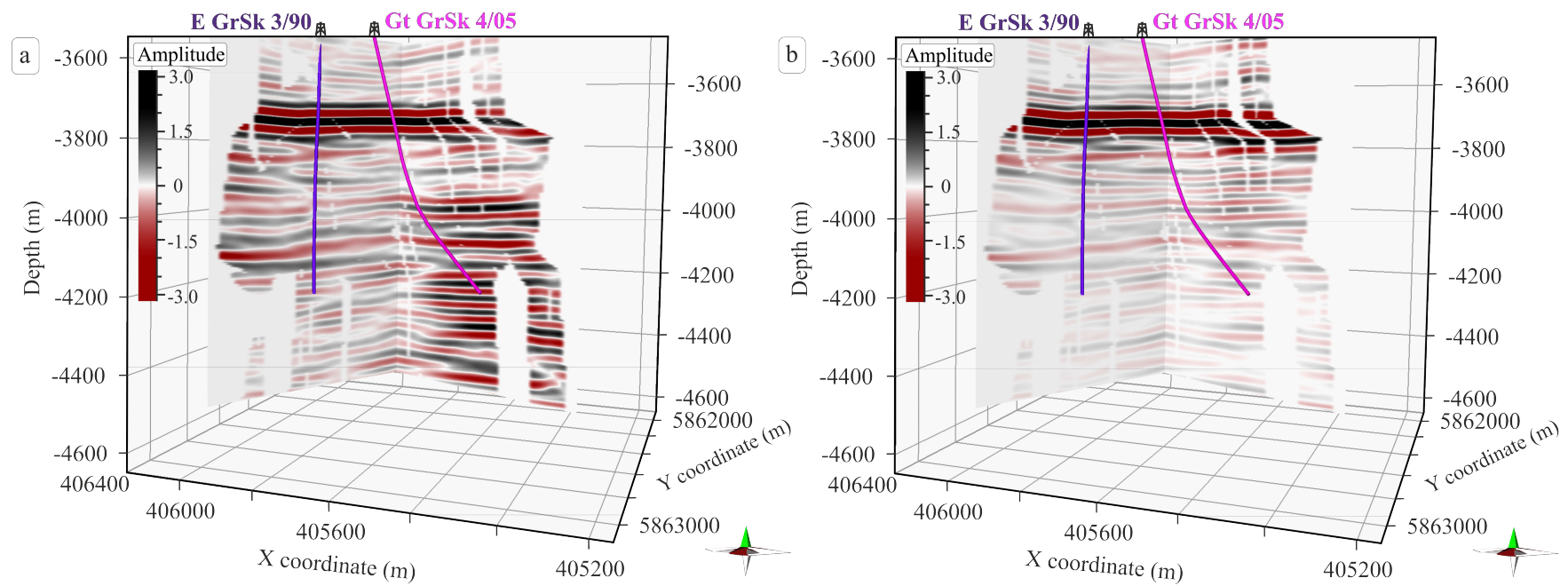

Figure 5. A comparison of 3D DAS VSP cubes generated with a model-based Kirchhoff migration algorithm (a) without and (b) with MPD denoising.

The suppression of the ringing noise by means of MPD denoising and amplitude normalisation techniques, significantly improved the imaging results. Figure 5a shows the result of the migration which excludes denoising from the processing 
https://doi.org/10.5194/se-2021-138

Preprint. Discussion started: 15 November 2021

(c) Author(s) 2021. CC BY 4.0 License.

\section{(c) (i)}

flow. The first problem that can be noticed are inconsistent significant amplitudes anomalies, especially clearly visible around borehole Gt GrSk 4/05 (Figure 5a) in the reservoir section from $4000 \mathrm{~m}$ till $4500 \mathrm{~m}$ depth. Apart from that, the "noisy" cube has decreased resolution and horizon continuity in comparison with a "clean" cube (Figure 5b).

\section{Reservoir imaging}

The resulting 3D DAS VSP cube image is $1600 \mathrm{~m}$ x $2000 \mathrm{~m}$, which has a relatively limited illumination range with a maximum inline/crossline extent of less than $900 \mathrm{~m}$. The image of the subsurface is the most complete and best around the boreholes. Reflections in the vicinity of the wells reach up to $4500 \mathrm{~m}$ depth (Figure 6). To interpret the 3D DAS VSP imaging results (Figure 6a), we compare it with the 3D surface seismic cube (Krawczyk et al., 2019; Norden et al., in preparation) after prestack depth migration (Figure 6b). The polarity of the DAS data was changed to match the polarity of the geophones. The 3D surface seismics was clipped according to the 3D DAS VSP cube layout. Bin size for borehole volume is $12.5 \mathrm{~m} \times 12.5 \mathrm{~m}$ and for surface seismic volume is $25 \mathrm{~m} \times 25 \mathrm{~m}$. This means that inlines / crosslines of the 3D DAS VSP cube are 2 times denser.

The reservoir section is situated at a depth interval between $4-4.5 \mathrm{~km}$ and has an average velocity of $4700 \mathrm{~m} / \mathrm{s}$; the dominant frequencies in 3D surface seismics are between 20 and $50 \mathrm{~Hz}$. With wireline 3D DAS VSP the frequencies are from 30 to 70 $\mathrm{Hz}$. This gives a vertical resolution estimation of $24-47 \mathrm{~m}$ for the conventional surface seismic cube and a more favourable 16 - $34 \mathrm{~m}$ for the borehole seismic dataset.

Several reflectors can be mapped with high confidence across both volumes. Especially the main marker horizons of the typical stratigraphy in the North German Basin were successfully imaged (Figure 6) : top Staßfurt-Basalanhydrit Fm $\left(Z_{1}\right)$, top Rotliegend $\left(Z_{3}\right)$, top of Hannover Fm. $\left(\mathrm{R}_{1}\right)$, top of Dethlingen Fm $\left(\mathrm{R}_{3}\right)$, top and the bottom Elbe basis sandstone (EBS) layers, and possibly top of the Carboniferous $\left(\mathrm{R}_{8}\right)$. Although both cubes have similarities, there are distinct differences related to the higher vertical resolution of the VSP measurements. In the following chapters we will focus on each structural feature separately.

\subsection{Upper Rotliegend horizons}

185 The most prominent reflections in both seismic cubes are closely situated reflection bands from the transition from salt to anhydrite (Staßfurt-Basalanhydrit Fm $\left(Z_{1}\right)$ ), followed by the reflection $Z_{3}$ from the base of Zechstein. Together these closely situated seismic responses create a complex wavelet superimposition consisting out of 5 phases. (Figure 6). Salt layers are underlayed by upper Rotliegend sediments.

For the first time in the area of the research platform Groß Schönebeck, borehole seismics allows the separation of thin interlaying of siltstone and silty mudstone structures in the upper Rotliegend sediments in the depth range from $3800 \mathrm{~m}$ to $4000 \mathrm{~m}$ (Figure 6a, light green arrow (1)). On the 3D surface seismics (Krawczyk et al., 2019; Norden et al., in preparation) a thick unresolved high amplitude continuous layer with visible thickness variations can be observed at approximately $3900 \mathrm{~m}$ (Figure 6b, light green arrow (1)). In contrast to the 3D surface seismic cube, on the 3D DAS VSP cube, two closely situated thin layers can be traced with a relatively constant thicknesses (Figure 6a, light green arrow (1)). 

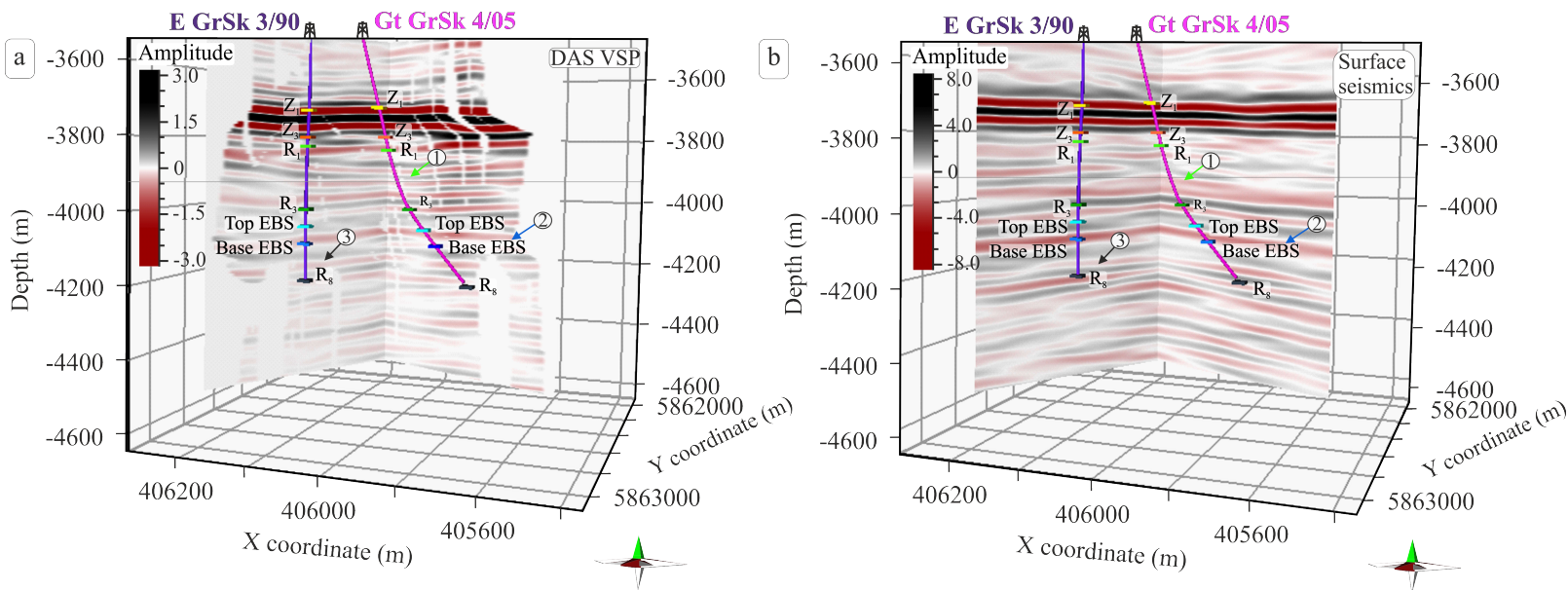

Figure 6. A comparison of 3D DAS VSP cube (a) and prestack depth migrated 3D surface seismic cube (b). Arrows with numbers highlight major interpretation features in the 3D DAS VSP and 3D surface seismic cubes. Light green arrows (1) point out the difference in seismic resolution in the upper Rotliegend; dark blue arrows (2) show the position of the Elbe basis sandstone horizon. Dark grey arrows (3) mark the location of unconformity in lower Rotliegend formation. Main seismic reflectors labelled on the figures: top Staßfurt-Basalanhydrit Fm $\left(\mathrm{Z}_{1}\right)$, top Rotliegend $\left(\mathrm{Z}_{3}\right)$, top of Hannover Fm $\left(\mathrm{R}_{1}\right)$, top of Dethlingen Fm $\left(\mathrm{R}_{3}\right)$, Top EBS - top Elbe basis sandstone, Base EBS - base Elbe basis sandstone, $\mathrm{R}_{8}$ - Base Effusive Rotliegend.

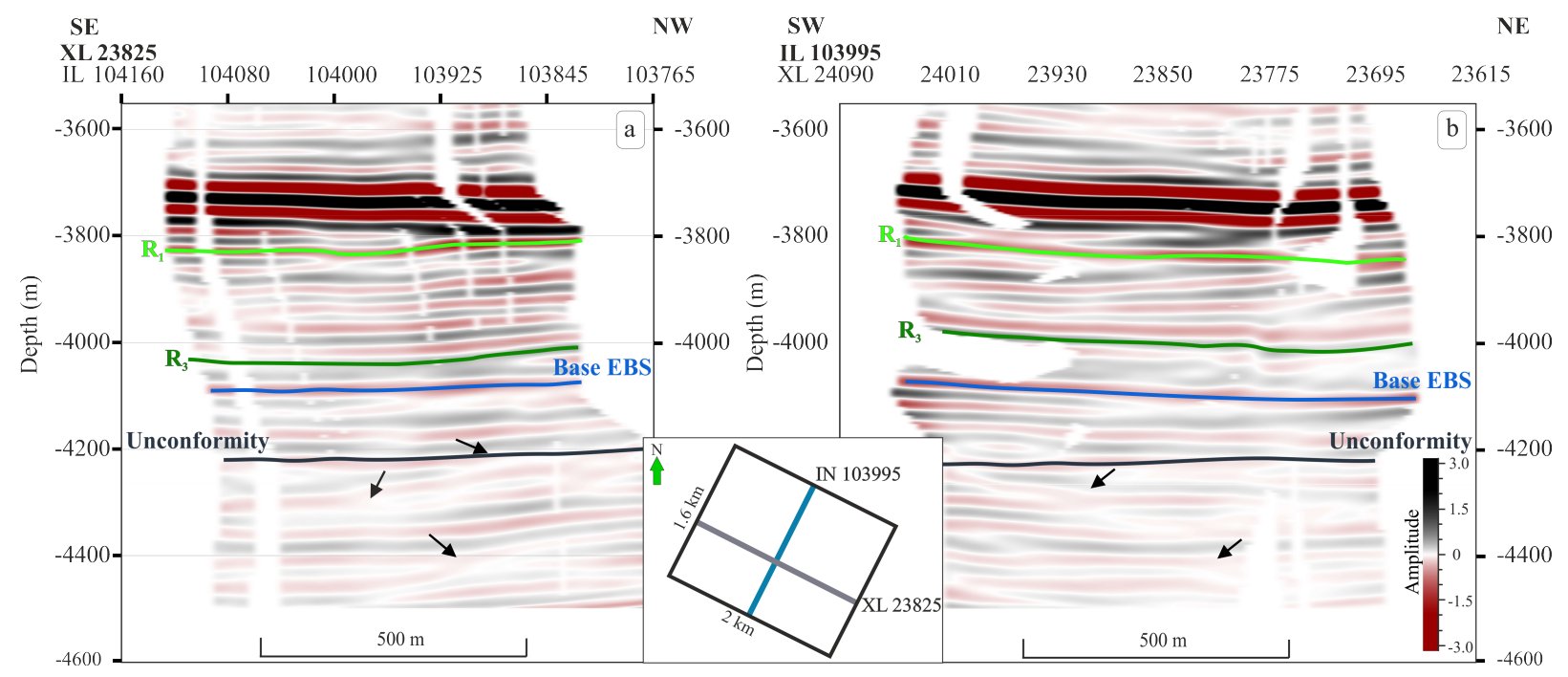

Figure 7. Seismic lines extracted from the 3D DAS VSP cube with horizons interpretation. (a) Seismic cross-line and (b) seismic inline, showing thin interlayered horizons in the upper Rotliegend (light green and dark green lines), base of the Elbe basis sandstone horizon (dark blue line) and the Lower Rotliegend unconformity (dark grey line). Black small arrows point out the locations of the numerous pinch outs. 
https://doi.org/10.5194/se-2021-138

Preprint. Discussion started: 15 November 2021

(c) Author(s) 2021. CC BY 4.0 License.

(c) (i)

By comparing the depth sections between $3800 \mathrm{~m}$ and $4000 \mathrm{~m}$ on both cubes, it can be noted that thin interlaying horizons in the 3D DAS VSP cube have various dipping characteristics, whereas the 3D surface seismic cube shows only thicker horizontal lines, sometimes even not continuous and with amplitudes variations along them. This might be related to the broader frequency content between surface and borehole seismics surveys, and as a result with the latter case having a higher resolution. The results of 3D DAS VSP imaging allows to trace a few thin horizons in the upper Rotliegend interval. Figure 7 demonstrates the inline and the crossline extracted from the central part of the seismic cube with interpreted horizons corresponding to top Hannover $\left(\mathrm{R}_{1}\right)$ and top Dethlingen Fm. $\left(\mathrm{R}_{3}\right)$. Depth variations of this horizons are visible already in a small volume around the boreholes. The indication of these variations in lithological sequences is also present in the corridor stacks within this interval (Henninges et al., 2021).

\subsection{Elbe basis sandstone layer}

One of the possible targets for geothermal exploration are sandstones of the Dethlingen formation / Lower Elbe subgroup. In the Brandenburg area the lower part of the Dethlingen formation comprises grained sandstone with high quality reservoir properties (porosity 8-10\% and permeability of $10-100 \mathrm{mD}$ (Trautwein and Huenges, 2005)), which has been deposited in a fluviatile setting. This geological unit, also known as the Elbe basis sandstone layer, was successfully imaged on both 3D images (Figure 6, dark blue arrows (2)).

In the conventional surface seismic image (Krawczyk et al., 2019; Norden et al., in preparation), the base EBS horizon can be traced as a continuous negative phase at around $4080 \mathrm{~m}$ depth, with increasing thickness toward the southwest direction. Even the theoretical resolution should be between 24 - $47 \mathrm{~m}$. Bauer et al. (2020) showed via finite-difference forward modelling that this complex layer in the reservoir section still won't be adequately resolved since the theoretical resolution cannot be achieved due to challenging geological settings above and below the EBS.

The high resolution of the 3D DAS VSP cube allows to trace depth variations of the Elbe basis sandstone horizon. We picked this horizon through the entire volume and created a depth contour map (Figure 8a). The map was clipped using a dark blue polygon shown on Figure 4a, to avoid interpolation artefacts in the regions with low coverage. The base EBS horizon lies at $4080 \mathrm{~m}$ on the southwest and at approximately $4100 \mathrm{~m}$ depth on the northeast. On the seismic section (Figure $8 \mathrm{~b}$ ), it is clearly visible that there is a pinch out on the southwest part of the profile, which was not distinguishable on the 3D surface seismics cube and visible as a thickness variation.

The top of the EBS horizon (Figure 9a) in general follows similar paleo relief of the base EBS with the deepest values around $4050 \mathrm{~m}$ in the southwest and $4080 \mathrm{~m}$ in the northeast. However, local depth variations are present, and therefore the thickness of the Elbe basis sandstone layer is highly variable in close proximity to the boreholes (Figure 9b). It ranges from 20 to $35 \mathrm{~m}$. 
https://doi.org/10.5194/se-2021-138

Preprint. Discussion started: 15 November 2021

(c) Author(s) 2021. CC BY 4.0 License.
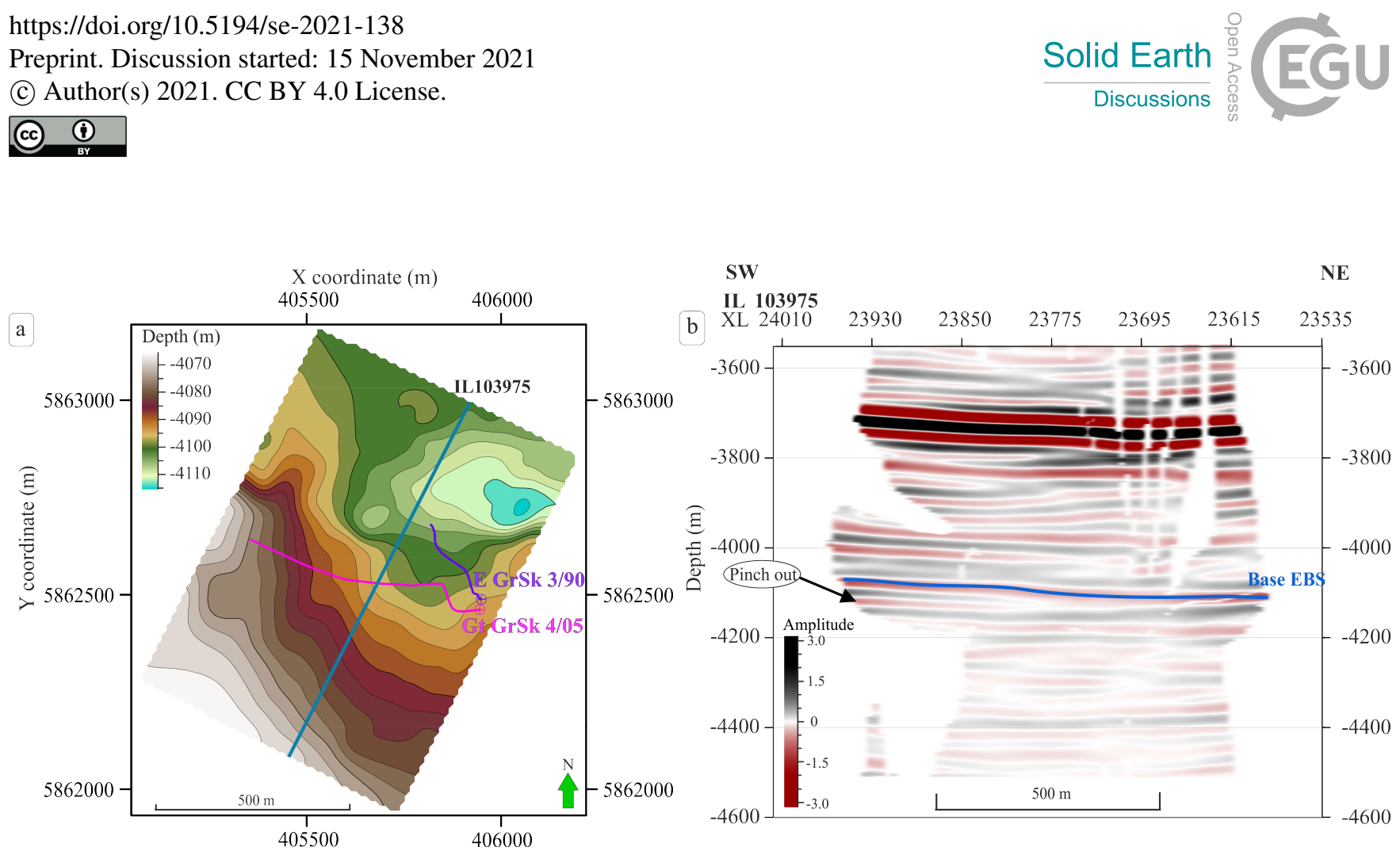

Figure 8. (a) Spatial extent of the Elbe basis sandstone layer. Depth contour map of the Elbe basis sandstone bottom horizon. The dark blue line marks the location of the inline shown in (b): seismic section from the 3D DAS VSP volume with the interpretation of the Elbe basis sandstone (EBS) horizon.
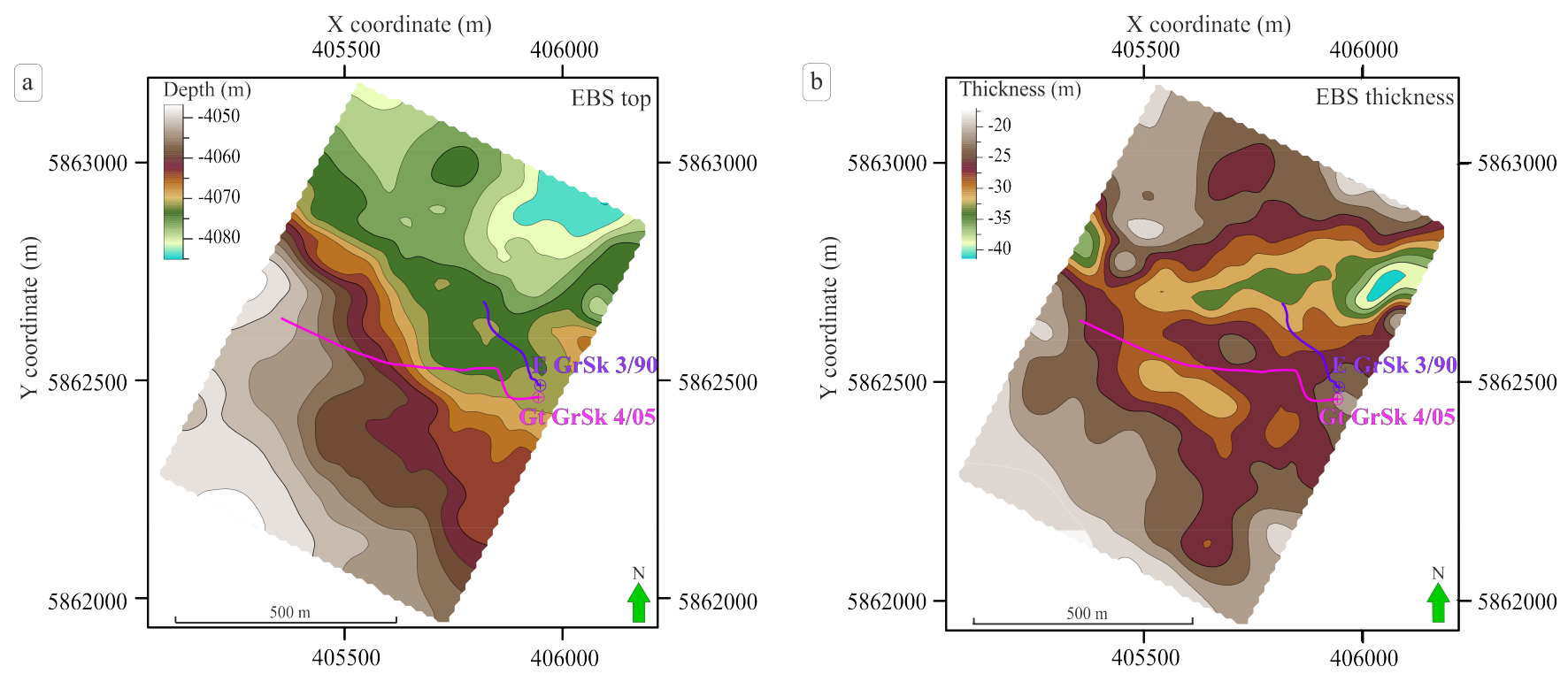

Figure 9. Mapping results within the study area: depth contour map of the top Elbe basis sandstone layer (a) and the EBS thickness (b). 
https://doi.org/10.5194/se-2021-138

Preprint. Discussion started: 15 November 2021

(c) Author(s) 2021. CC BY 4.0 License.

(c) (i)

\subsection{The lower Rotliegend unconfomity}

Another essential feature of the seismic interpretation on the 3D DAS VSP and the 3D surface seismics (Krawczyk et al., 2019; Norden et al., in preparation) cubes is the change in seismic reflection pattern (Figure 6) at a depth around $4200 \mathrm{~m}$. On the 3D surface seismics, this is visible as a change from horizontal continuous reflectors to layers with inconsistent amplitudes and a lower reflectivity in the lower Rotlieged formation (Figure 6b, the dark grey arrow (3)). On the 3D DAS VSP cube, a change from nearly horizontal to inclined reflectors can be detected (Figure 6a, the dark grey arrow (3)). This change of the seismic facies evidences the existence of an unconformity in the area where we expect volcanic rocks. We will refer to it as lower Rotliegend unconfomity.

On the seismic cross-line and inline shown in Figure $7 \mathrm{a}$ and $\mathrm{b}$, the possible unconformity boundary is marked by a thick dark grey line. This reflection has weak, uncertain characteristics. Small black arrows indicate numerous exciting pinch outs below this horizon, which were used as indicators of the type change of the layering. Due to reduced reflectivity and gaps in the cubes, tracing this horizon accurately is a pretty challenging task. Therefore the resulting depth contour map might have errors, especially at the edges of the dataset. Nevertheless, in the area between two boreholes where we have the best coverage, we can see that the depth variation of the lower Rotliegend unconformity is relatively limited to the depth range between 4200 - $4230 \mathrm{~m}$ (Figure 10).

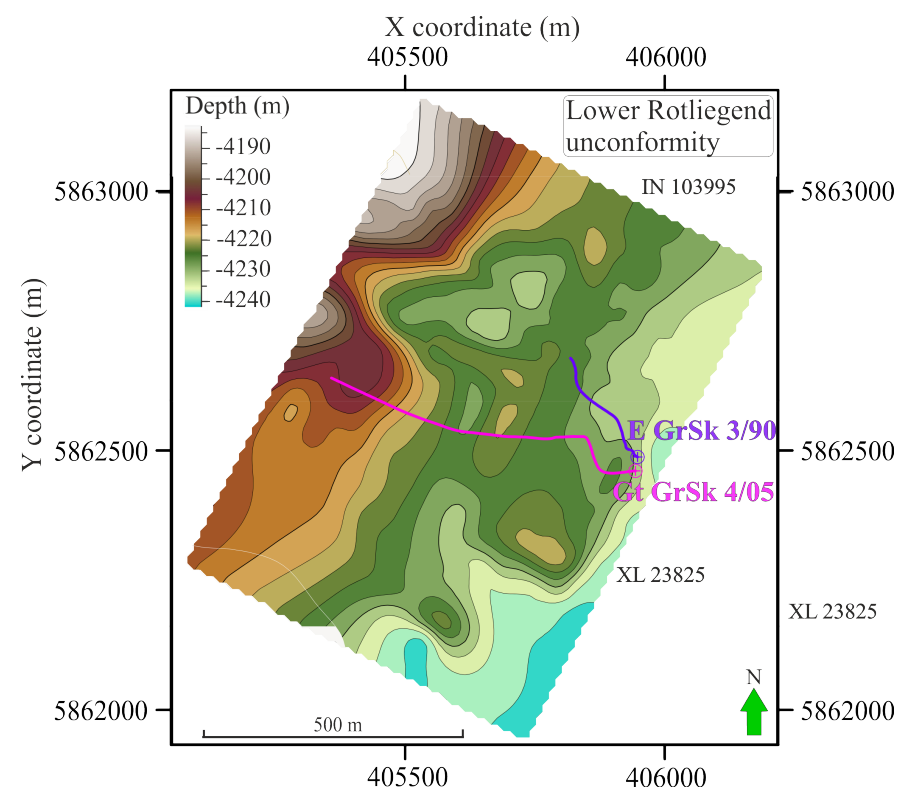

Figure 10. Spatial distribution of the unconformity boundary. Depth of the Lower Rotliegend unconformity. 
https://doi.org/10.5194/se-2021-138

Preprint. Discussion started: 15 November 2021

(c) Author(s) 2021. CC BY 4.0 License.

\section{Discussion \& Outlook}

240

\subsection{The Groß Schönebeck experiment}

With this study, we investigated the applicability of the DAS wireline acquisition method for detailed deep geothermal reservoir imaging and the capability to bridge the gap between well logs and 3D surface seismics. 3D DAS VSP provides, on average, two times better-resolved image than 3D surface seismic and has a significant potentical in the geothermal sector. Data acquisition using constellation fibres or new interrogators with higher signal-to-noise ratio can help notably improve the quality of the wireline DAS data recording and compensate for signal loses in the deep reservoir section. Nethertheless, more research on fibre coupling improvement and location control in the borehole is strongly advised, which could allow wireline DAS acquisition to become a routine for numerous applications.

VSP surveys conducted with distributed sensors permanently installed behind casing or along the tubing provide the advantage of good coupling conditions and the possibility to perform time-lapse studies. Successfully reported case studies include applications for unconventional exploration in Texas (Shultz and Simmons, 2019) to create a detailed image of the formation around the well. Application of DAS for CO2 monitoring (Götz et al., 2018; Correa et al., 2019) is a well-known routine to provide a reliable method for targeted, detailed imaging and 4D monitoring of the site. 3D DAS VSP surveys in oil and gas exploration reduce exploration risks in regions with a challenging environment, for instance, in the presence of strong production noise (Jiang et al., 2016), in areas with complex salt tectonics (Bartels et al., 2015) etc. In general, all the surveys mentioned above have a better signal-to-noise ratio than data typically recorded with wireline DAS acquisition.

Wireline DAS, however, has a great advantage. It allows to acquire seismic data in already drilled and cemented boreholes. This can be done at a low cost and in a small amount of time. Even though wireline 3D DAS VSP at the Groß Schönebeck site has worse coupling conditions than conventional DAS cemented behind the casing, the resolution of the imaged seismic volume is still in the same range of $20 \mathrm{~m}$.

To the best of the authors knowledge, there are only limited examples of wireline DAS applications with active seismic sources for geothermal exploration. One known example was recorded in 2016 at the geothermal field at Brady Hot Springs, Nevada (Miller et al., 2018). A fibre optical cable was deployed into the accessible $363 \mathrm{~m}$ portion of the vertical well 56-1. This dataset has a limited depth range (up to $297 \mathrm{~m}$ only), and only two shot points were used for data acquisition. No 3D image was created. Therefore, the experiments conducted at the Groß Schönebeck in-situ laboratory and Brady Hot Springs are quite different and it is problematic to compare these two datasets. Thus, recorded data at the Groß Schönebeck is unique among the experiments conducted for geothermal exploration, with reflection information recorded down to $4.2 \mathrm{~km}$ deep.

A spiral survey design at the Groß Schönebeck site led to a ray focusing on the target reservoir area yielding an equably distributed offset and azimuth coverage. Good results were achieved with only 61 VPs. Nevertheless, low to zero ray coverage in some regions of the 3D VSP survey resulted in a lack of data required for a successful migration process without excessive artefacts. Due to budget limitations, the number of vibrator points had to be restricted and quite often positioned in such a way that they don't have overlapping ray penetrating areas. Therefore, petal-shaped footprints, with the highest coverage in the centre, are prominent in bin density slices (Figure 4a) revealing a partial illumination problem. Consequently, the resulting 
https://doi.org/10.5194/se-2021-138

Preprint. Discussion started: 15 November 2021

(c) Author(s) 2021. CC BY 4.0 License.

\section{(c) (i)}

migrated depth slices have gaps and are not well suitable for classical attribute analysis. These limitations led to the usage of the 3D DAS VSP cube for structural interpretation only.

A similar experiment to the Groß Schönebeck survey was conducted for hydrocarbons exploration in China's Heibei region (Yu et al., 2016). DAS walkaway and walkaround VSP with wireline survey consisted of 386 successful shot points, 6 times more than at the Groß Schönebeck experiment. The data acquisition for the in-situ laboratory in the Brandenburg area was probably less time-consuming, effortful and costly than this experiment in China. However, densely regularly placed source positions allowed to get a detailed resolved 3D image for the area of interest in Heibei region without gaps and prominent migration artefacts. The experiment in China showed that with a larger amount of source points a better coverage can be achieved, however, one should always look for a trade off between a reasonable coverage and acquisition cost during the planning phase.

\subsection{Data processing}

The experiment at the Groß Schönebeck allowed gaining valuable knowledge on survey planning and data processing. One of the biggest challenges for this dataset was a ringing noise problem. At the early stages of the data processing, an intermediate solution for denoising included the Burg adaptive deconvolution combined with careful exclusion of depth intervals with a poor signal-to-noise ratio from the data processing. To further improve imaging results and limit migration artefacts due to sparse coverage, it was necessary to improve the signal-to-noise ratio of the data and include more data into migration calculations. Therefore, an essential part in successful data imaging results played careful denoising using the MPD approach.

Besides the quantity of the data, another important parameter, which will significantly influence the imaging results, is the migration aperture (Schleicher et al., 1997; Sun, 2000). After extensive testing we came to the conclusion that a strict restriction of $5^{\circ}$ can lead to an ambiguous and inconsistent summation of the main horizons. On the other hand, a too broad aperture can reduce the resolution of the horizons. Thus, a compromise between these parameters should be found. Additionally, due to its stacking nature, the migration operator will also attenuate to some extent the residual noise in the data.

\subsection{Future geothermal exploration plans}

The results of our 3D DAS VSP experiments prove that this type of measurement can significantly contribute to exploration campaigns. The wireline DAS VSP allows reducing risks and can have a higher resolution compared to the conventional 3D surface seismics interpretation does not provide enough information due to the limited resolution of the data.

The Elbe basis sandstone layer currently represent one of potential targets for the future geothermal exploration. The 3D VSP imaging results clarified the sandstone layer's effective thickness with good reservoir properties. According to our estimations, it varies between 25 to $40 \mathrm{~m}$ (Figure $9 \mathrm{~b}$ ) near the boreholes locations. The fluvial nature of these deposits is perhaps responsible for this high variability. Previously the thickness of this layer was overestimated to be around $80 \mathrm{~m}$ (Zimmermann et al., 2010). Our results are also supported by updated thicknesses from the 3D surface seismic experiment, calculated using wavelet transform-based seismic facies classification (Bauer et al., 2020; Norden et al., in preparation). 
An assessment of the geothermal resources depends on the geothermal reservoir's geological formation and thermal and hydraulic properties. One of many parameters required to estimate the geothermal reservoir heat capacity include reservoir volume, which is determined as a product of reservoir area and reservoir thickness. The heat stored in the geothermal reservoir is linearly dependent on the volume reservoir, which directly depends on the thickness of the reservoir (Garg and Combs, 2015). In other words, the thinner the reservoir, the lower the extracted heat. Therefore, according to the new information, the planned economical operation analysis for the heat extraction from Elbe basis sandstone should be reevaluated.

At the depth level around $4200 \mathrm{~m}$, we mapped lower the Rotliegend unconformity. There is a hypothesis that deposits of permo-carboniferous volcanic rocks lay below this border, which represent another possible target for future exploration (Norden et al., in preparation). The 3D DAS VSP imaging successfully contributed to the determination of this critical boundary since it was not well characterised on the 3D surface seismics cube. The bottom of permo-carboniferous volcanic rocks is not detectable neither on the 3D DAS VSP nor on the 3D surface seismic cubes. This implies that the thickness of this deposit's sections can be greater than $300 \mathrm{~m}$. Considering this information, the economic profitability is significantly higher for treated volcanic rocks than for the Elbe basis sandstone layer. Nevertheless, we believe it is crucial to determine the exact depth by drilling, perform core analysis, and use well logging methods to determine the precise composition of sediments below this border and essential parameters such as porosity and permeability before developing concepts for possible reservoir treatments in volcanites.

The exact development plans of the site are still under discussion. Possible scenarios include implementing a new stimulation concept and possibly drilling a new well (GrSk 5) or deepening the existing borehole E GrSk 3/90.

\section{Conclusions}

We analysed the 3D DAS VSP imaging results acquired with wireline DAS installation at the Groß Schönebeck geothermal research site. Despite the numerous difficulties during the data acquisition campaign, the borehole seismics was able to image the target interval and substantially contribute to the detailed interpretation of the geothermal reservoir.

The 3-dimensional image created using borehole yields:

- Resolution of thin complex upper Rotliegent geological structure;

- Mapping of the target base Elbe basis sandstone horizon;

- Detection of the lower Rotliegend unconformity in the region with possible volcanic rocks.

The interpretation of the 3D DAS VSP cube evidenced the unexpected absence of faults with larger vertical offsets and fractures. Furthermore, no indications for free gas were found in the data. These findings are important for the further development of the Groß Schönebeck in-situ geothermal laboratory.

Wireline DAS is still a relatively new method. It allows for a significantly increase in the number of sensors and a larger recording aperture, which results in imaging over a larger depth interval. Thus, it is cheaper and faster than the application of 
https://doi.org/10.5194/se-2021-138

Preprint. Discussion started: 15 November 2021

(c) Author(s) 2021. CC BY 4.0 License.

(c) (i)

Discussions

conventional borehole sensors. Nevertheless, careful survey planning and sophisticated data processing are vital for successful imaging results.

A successful case study at the Groß Schönebeck site can play a crucial role in developing and applying modern, efficient geothermal exploration methods in the Northern German Basin and other regions with comparable lithology.

Author contributions. EM performed the seismic data processing and analysis. EM interpreted the data under discussion with CMK. EM and CMK discussed the results and contributed to the final manuscript. CMK supervised the project.

Competing interests. The authors declare that they have no conflict of interest. Charlotte M. Krawczyk is chief executive editor of SE.

Acknowledgements. Funding of the present work was provided by the German Federal Ministry of Economic Affairs and Energy (grant 0324065), and the European Commission, Horizon 2020 Framework Programme (grant nos. DESTRESS (691728) and EPOS IP (676564)). We would like to thank all contractors involved in the acquisition and processing. The authors would like sincerely to acknowledge Ernst Huenges for establishing research activities at the Groß Schönebeck in-situ geothermal laboratory, Manfred Stiller, Jan Henninges and Klaus Bauer for experiment planning, supervision of the fieldwork and data acquisition, as well as constructive discussions on data processing. We also thank all our colleagues from GFZ German Research Centre for Geosciences for their contribution to this work. The authors also acknowledge James Bailey, Mary Humphries and Colin Humphries for providing VSProwess software and sharing their extensive VSP data processing knowledge. 
https://doi.org/10.5194/se-2021-138

Preprint. Discussion started: 15 November 2021

(c) Author(s) 2021. CC BY 4.0 License.

(c) (i)

\section{References}

Bartels, T., Gelhaus, M., and Humphries, M.: VSP Measurements Used as a Tool for Sub Salt Near Field Development, in: 77th EAGE Annual Meeting, Expanded Abstracts, p. We N104 15, https://doi.org/https://doi.org/10.3997/2214-4609.201412918, 2015.

Bauer, K., Norden, B., Ivanova, A., Stiller, M., and Krawczyk, C. M.: Wavelet transform-based seismic facies classification and modelling: application to a geothermal target horizon in the NE German Basin, Geophysical Prospecting, 68, 466-482, https://doi.org/https://doi.org/10.1111/1365-2478.12853, 2020.

Bellefleur, G., Schetselaar, E., Wade, D., White, D., Enkin, R., and Schmitt, D. R.: Vertical seismic profiling using distributed acoustic sensing with scatter-enhanced fibre-optic cable at the $\mathrm{Cu}-\mathrm{Au}$ New Afton porphyry deposit, British Columbia, Canada, Geophysical Prospecting, 68, 313-333, https://doi.org/https://doi.org/10.1111/1365-2478.12828, 2020.

Blöcher, G., Reinsch, T., Henninges, J., Milsch, H., Regenspurg, S., Kummerow, J., Francke, H., Kranz, S., Saadat, A., Zimmermann, G., and Huenges, E.: Hydraulic history and current state of the deep geothermal reservoir Groß Schönebeck, Geothermics, 63, 27-43, https://doi.org/https://doi.org/10.1016/j.geothermics.2015.07.008, enhanced Geothermal Systems: State of the Art, 2016.

Booth, A. D., Christoffersen, P., Schoonman, C., Clarke, A., Hubbard, B., Law, R., Doyle, S. H., Chudley, T. R., and Chalari, A.: Distributed Acoustic Sensing of Seismic Properties in a Borehole Drilled on a Fast-Flowing Greenlandic Outlet Glacier, Geophysical Research Letters, 47, e2020GL088 148, https://doi.org/https://doi.org/10.1029/2020GL088148, e2020GL088148 2020GL088148, 2020.

Brisbourne, A. M., Kendall, M., Kufner, S.-K., Hudson, T. S., and Smith, A. M.: Downhole distributed acoustic seismic profiling at Skytrain Ice Rise, West Antarctica, The Cryosphere Discussions, 2021, 1-18, https://doi.org/https://doi.org/10.5194/tc-2021-1, 2021.

Correa, J., Pevzner, R., Bona, A., Tertyshnikov, K., Freifeld, B., Robertson, M., and Daley, T.: 3D vertical seismic profile acquired with distributed acoustic sensing on tubing installation: A case study from the CO2CRC Otway Project, Interpretation, 7, SA11-SA19, https://doi.org/https://doi.org/10.1190/INT-2018-0086.1, 2019.

Dean, T., Cuny, T., and Hartog, A. H.: The effect of gauge length on axially incident P-waves measured using fibre optic distributed vibration sensing, Geophysical Prospecting, 65, 184-193, https://doi.org/https://doi.org/10.1111/1365-2478.12419, 2017.

Dillon, P. B. and Thomson, R. C.: OFFSET SOURCE VSP SURVEYS AND THEIR IMAGE RECONSTRUCTION*, Geophysical Prospecting, 32, 790-811, https://doi.org/https://doi.org/10.1111/j.1365-2478.1984.tb00739.x, 1984.

Dou, S., Lindsey, N., Wagner, A. M., Daley, T. M., Freifeld, B., Robertson, M., Peterson, J., Ulrich, C., Martin, E. R., and Ajo-Franklin, J. B.: Distributed Acoustic Sensing for Seismic Monitoring of The Near Surface: A Traffic-Noise Interferometry Case Study, Scientific Reports, 7, 11 620, https://doi.org/10.1038/s41598-017-11986-4, 2017.

Garg, S. K. and Combs, J.: A reformulation of USGS volumetric "heat in place" resource estimation method, Geothermics, 55, 150-158, https://doi.org/https://doi.org/10.1016/j.geothermics.2015.02.004, 2015.

Götz, J., Lüth, S., Henninges, J., and Reinsch, T.: Vertical seismic profiling using a daisy-chained deployment of fibre-optic cables in four wells simultaneously - Case study at the Ketzin carbon dioxide storage site, Geophysical Prospecting, 66, 1201-1214, https://doi.org/https://doi.org/10.1111/1365-2478.12638, 2018.

Henninges, J., Baumann, G., Brandt, W., Cunow, C., Poser, M., Schrötter, J., and Huenges, E.: A Novel Hybrid Wireline Logging System for Downhole Monitoring of Fluid Injection and Production in Deep Reservoirs, in: 73rd EAGE Conference \& Exhibition, Expanded Abstracts, https://doi.org/https://doi.org/10.3997/2214-4609.20149727, 2011. 
https://doi.org/10.5194/se-2021-138

Preprint. Discussion started: 15 November 2021

(c) Author(s) 2021. CC BY 4.0 License.

(c) (i)

Henninges, J., Martuganova, E., Stiller, M., Norden, B., and Krawczyk, C. M.: Wireline distributed acoustic sensing allows $4.2 \mathrm{~km}$ deep vertical seismic profiling of the Rotliegend $150^{\circ} \mathrm{C}$ geothermal reservoir in the North German Basin, Solid Earth, 12, 521-537, https://doi.org/https://doi.org/10.5194/se-12-521-2021, 2021.

Hudson, T., Baird, A., Kendall, J., Kufner, S., Brisbourne, A., Smith, A., Butcher, A., Chalari, A., and Clarke, A.: Distributed Acoustic Sensing in Antarctica: What we can learn for studying microseismicity elsewhere, Conference Proceedings, EAGE GeoTech 2021 Second EAGE Workshop on Distributed Fibre Optic Sensing, pp. 1-5, https://doi.org/https://doi.org/10.3997/2214-4609.202131037, 2021.

Humphries, M., Vidal, J., and de Dios, J.: VSP Monitoring for CO2 Migration Tracking in Fractured Rock Massifs, in: 77th EAGE Conference and Exhibition, no. 1 in Expanded Abstracts, pp. 1-5, European Association of Geoscientists \& Engineers, https://doi.org/https://doi.org/10.3997/2214-4609.201412672, 2015.

Jiang, T., Zhan, G., Hance, T., Sugianto, S., Soulas, S., and Kjos, E.: Valhall dual-well 3D DAS VSP field trial and imaging for active wells, in: 86th SEG Annual Meeting, Expanded Abstracts, pp. 5582-5586, https://doi.org/https://doi.org/10.1190/segam2016-13871754., 2016.

Krawczyk, C. M.: Wie Glasfaserkabel als Geosensoren zur Erkundung und Überwachung des Untergrunds genutzt werden können - Anwendungen und Potenzial von ortsverteilten faseroptischen Messungen (How fibre optic cables can be used as geosensors to explore and monitor the subsurface - Applications and Potential of distributed acoustic sensing)., Brandenburgische Geowiss. Beiträge, in review.

Krawczyk, C. M., Stiller, M., Bauer, K., Norden, B., Henninges, J., Ivanova, A., and Huenges, E.: 3-D seismic exploration across the deep geothermal research platform Groß Schönebeck north of Berlin/Germany, Geothermal Energy, 7, 15, https://doi.org/https://doi.org/10.1186/s40517-019-0131-x, 2019.

Lellouch, A., Schultz, R., Lindsey, N., Biondi, B., and Ellsworth, W.: Low-Magnitude Seismicity With a Downhole Distributed Acoustic Sensing Array-Examples From the FORGE Geothermal Experiment, Journal of Geophysical Research: Solid Earth, 126, e2020JB020 462, https://doi.org/https://doi.org/10.1029/2020JB020462, e2020JB020462 2020JB020462, 2021.

Li, Z. and Zhan, Z.: Pushing the limit of earthquake detection with distributed acoustic sensing and template matching: a case study at the Brady geothermal field, Geophysical Journal International, 215, 1583-1593, https://doi.org/10.1093/gji/ggy359, 2018.

Lior, I., Sladen, A., Rivet, D., Ampuero, J.-P., Hello, Y., Becerril, C., Martins, H. F., Lamare, P., Jestin, C., Tsagkli, S., and Markou, C.: On the Detection Capabilities of Underwater Distributed Acoustic Sensing, Journal of Geophysical Research: Solid Earth, 126, e2020JB020 925, https://doi.org/https://doi.org/10.1029/2020JB020925, e2020JB020925 2020JB020925, 2021.

Lizarralde, D. and Swift, S.: Smooth inversion of VSP traveltime data, GEOPHYSICS, 64, 659-661, https://doi.org/https://doi.org/10.1190/1.1444574, 1999.

Martuganova, E., Stiller, M., Bauer, K., Henninges, J., and Krawczyk, C. M.: Cable reverberations during wireline distributed acoustic sensing measurements: their nature and methods for elimination, Geophysical Prospecting, 69, 1034-1054, https://doi.org/https://doi.org/10.1111/1365-2478.13090, 2021.

Miller, D., Coleman, T., Zeng, X., Patterson, J., Reinisch, E., Wang, H., Fratta, D., Trainor-Guitton, W., Thurber, C., Robertson, M., Feigl, K., and Team, T.: DAS and DTS at Brady Hot Springs: Observations about Coupling and Coupled Interpretations, in: 43rd Workshop on Geothermal Reservoir Engineering, Proceedings, 2018.

Moeck, I., Schandelmeier, H., and Holl, H.-G.: The stress regime in a Rotliegend reservoir of the Northeast German Basin, International Journal of Earth Sciences, 98, 1643-1654, https://doi.org/10.1007/s00531-008-0316-1, 2009.

Nishimura, T., Emoto, K., Nakahara, H., Miura, S., Yamamoto, M., Sugimura, S., Ishikawa, A., and Kimura, T.: Source location of volcanic earthquakes and subsurface characterization using fiber-optic cable and distributed acoustic sensing system, Scientific Reports, 11, 6319, https://doi.org/10.1038/s41598-021-85621-8, 2021. 
https://doi.org/10.5194/se-2021-138

Preprint. Discussion started: 15 November 2021

(c) Author(s) 2021. CC BY 4.0 License.

(c) (i)

Norden, B., Bauer, K., and Krawczyk, C. M.: The 3D structural model of the geothermal research platform Groß Schönebeck in the Northeast German Basin: new insights based on 3D seismics, in preparation.

Schleicher, J., Hubral, P., Tygel, M., and Jaya, M. S.: Minimum apertures and Fresnel zones in migration and demigration, Geophysics, 62, 183-194, https://doi.org/10.1190/1.1444118, 1997.

Shultz, W. and Simmons, J.: 3D DAS VSP in unconventionals: A case study, in: 89th SEG Annual Meeting, Expanded Abstracts, pp. 979983, https://doi.org/https://doi.org/10.1190/segam2019-3214518.1, 2019.

Spica, Z. J., Nishida, K., Akuhara, T., Pétrélis, F., Shinohara, M., and Yamada, T.: Marine Sediment Characterized by Ocean-Bottom Fiber-Optic Seismology, Geophysical Research Letters, 47, e2020GL088360, https://doi.org/https://doi.org/10.1029/2020GL088360, e2020GL088360 10.1029/2020GL088360, 2020a.

Spica, Z. J., Perton, M., Martin, E. R., Beroza, G. C., and Biondi, B.: Urban Seismic Site Characterization by Fiber-Optic Seismology, Journal of Geophysical Research: Solid Earth, 125, e2019JB018656, https://doi.org/https://doi.org/10.1029/2019JB018656, e2019JB018656 10.1029/2019JB018656, 2020b.

Stiller, M., Krawczyk, C. M., Bauer, K., Henninges, J., Norden, B., Huenges, E., and Spalek, A.: 3D-Seismik am Geothermieforschungsstandort Groß Schönebeck, BBR - Fachmagazin für Brunnen- und Leitungsbau, 1, 84—91, 2018.

Sun, J.: Limited-aperture migration, Geophysics, 65, https://doi.org/10.1190/1.1444754, 2000.

440 Thomsen, L.: Weak elastic anisotropy, GEOPHYSICS, 51, 1954-1966, https://doi.org/10.1190/1.1442051, 1986.

Trautwein, U. and Huenges, E.: Poroelastic behaviour of physical properties in Rotliegend sandstones under uniaxial strain, International Journal of Rock Mechanics and Mining Sciences, 42, 924-932, https://doi.org/https://doi.org/10.1016/j.ijrmms.2005.05.016, rock Physics and Geomechanics, 2005.

Wilson, G. A., Willis, M. E., and Ellmauthaler, A.: Evaluating 3D and 4D DAS VSP image quality of subsea carbon storage, The Leading Edge, 40, 261-266, https://doi.org/https://doi.org/10.1190/tle40040261.1, 2021.

Yu, G., Cai, Z., Chen, Y., Wang, X., Zhang, Q., Li, Y., Wang, Y., Liu, C., Zhao, B., and Greer, J.: Walkaway VSP using multimode optical fibers in a hybrid wireline, The Leading Edge, 35, 615-619, https://doi.org/https://doi.org/10.1190/tle35070615.1, 2016.

Yuan, S., Lellouch, A., Clapp, R. G., and Biondi, B.: Near-surface characterization using a roadside distributed acoustic sensing array, The Leading Edge, 39, 646-653, https://doi.org/https://doi.org/10.1190/tle39090646.1, 2020.

Zhan, G. and Nahm, J.: Multi-well 3D DAS VSPs: Illumination and imaging beyond the wellbores, in: 90th SEG Annual Meeting, Expanded Abstracts, pp. 3798-3802, https://doi.org/https://doi.org/10.1190/segam2020-3426032.1, 2020.

Zimmermann, G., Moeck, I., and Blöcher, G.: Cyclic waterfrac stimulation to develop an Enhanced Geothermal System (EGS)—Conceptual design and experimental results, Geothermics, 39, 59-69, https://doi.org/https://doi.org/10.1016/j.geothermics.2009.10.003, the European I-GET Project: Integrated Geophysical Exploration Technologies for Deep Geothermal Reservoirs, 2010. 